\title{
Razão, possessão, derrisão: três facetas das práticas divinatórias entre os romanos
}

\author{
PEDRO PAULO ABREU FUNARI \\ Departamento de História \\ Instituto de Filosofia e Ciências Humanas \\ Universidade Estadual de Campinas
}

\begin{abstract}
RESUMO: As práticas divinatórias romanas têm sido consideradas como uma prática unitária englobando representações ideológicas e práticas rituais. Este artigo busca discutir alguns aspectos da adivinhação tal como encarada pelos romanos do período republicano tardio e do início do principado tendo em vista suas contradições internas em termos tanto do pensamento como das práticas de adivinhação. $O$ autor estuda os principais pontos de vista a respeito. A articulação das diferentes interpretaçōes permite melhor compreender as tensōes e contradiçōes derivadas da adivinhação na sociedade romana.
\end{abstract}

PALAVRAS-CHAVE: Adivinhação, rituais, religião romana, sociedade romana.

\section{Introdução}

O que conhecemos, chamamos leis da Fatalidade; o que desconhecemos, chamamos livre arbitrio. $O$ livre arbitrio é para a História apenas uma expressão para designar o que não sabemos sobre as leis da vida humana

\section{Tostoi, Guerra e Paz.}

A adivinhação ${ }^{1}$ entre os romanos, apesar da abundância das fontes escritas e da bibliografia a respeito ${ }^{2}$ tem sido encarada por muitos autores a partir de um ponto de vista univoco ${ }^{3}$. No entanto, a sociedade romana não era composta de um só grupo social nem durante o decorrer de sua história mantiveram-se imutáveis as relações sociais. Pelo contrário, desde o inicio a história de Roma caracterizou-se por disputas e conflitos $^{4}$ entre grupos sociais e nem mesmo a pax romana viria anular esses conflitos ${ }^{5}$. Meu objetivo, portanto, não é tratar da adivinhação romana como uma prática social unitária e compatível internamente em suas manifestações mas, em sentido oposto, 
questionar as contradições internas inerentes à esfera da adivinhação no pensamento dos romanos.

Há pouco mais de uma década G. Dumézil $(1974$, p. 140) afirmava que "la divination ne se pratique pas dans l'enthousiasme, elle est le fait des froids interprètes des signes". Cícero, em seu tratado sobre a adivinhação, apresenta uma tipologia da leitura do futuro que demonstra uma outra concepção da questão:

Quae est autem gens aut quae ciuitas, quae non aut extispicium aut monstra aut fulgura interpretantium aut augurum aut austrologorum aut sortium (ea enim fere artis sunt) aut somniorum aut uaticinationum (haec enim dua naturalia putantur) [Cic./, Diu., 1, 6].

Que povo ou que estado não se deixa guiar pela predição derivada da leitura das entranhas, da interpretação dos prodígios, dos relâmpagos, dos pássaros, dos astros (estas são quase uma ciência) ou dos sonhos e das inspirações proféticas (estas duas são consideradas naturais)?

Em que medida, contudo, esta classificação de Cícero corresponde às diferentes maneiras de encarar a adivinhação prevalecentes em fins da República e no início do Princípado?

O que distingue ars (Cíc., Diu., 1, 8; Cíc., De Nat. Deorum, 2, 65) e natura (Cíc., Diu., 2, 72; Cíc., De Nat. Deorum, 2, 65; Sêneca, Nat. Quaest, Praef.) e ainda mais, o quanto se acreditava em cada tipo de predição? ${ }^{6}$.

Para responder a estas questões é necessário distinguir ao menos três tipos de comportamentos complementares dos romanos para com a adivinhação: 1. a leitura racional dos sinais; 2. possessão; e 3. a derrisão ou desprezo pela adivinhação. As três abordagens não são excludentes, pelo contrário, pois os autores latinos - e as poucas inscrições (CIL. 6, 36. 1841; 6, 503; 6, 504; 6, 1.449; 10, 211; 12, 410; Lex Vrsonensis 1, 4,31 ) e grafites ${ }^{7}$ a esse respeito - demonstram a um só tempo concordância e suspeita para com cada uma das práticas correntes ${ }^{8}$. Assim, embora se possa definir três campos diversos enquanto construção analítica da realidade, a interpenetração dessas esferas nos agentes sociais concretos não pode ser deixada de lado.

\section{A evidência da tradição textual}

The frightening decrees of Fate or Fortune. It is true that magical practices, of which there were very many at Pompeii, might also help to trick Fate. 
A adivinhação enquanto prática de leitura racional de sinais define-se como uma scientia (Cíc., de Nat. Deor., 2, 65; Sêneca, Nat. Quaest., 2, 32) ou seja, diuturna obseruatione alicuius rei scientiam efficere (Cíc., Div., 1, 2). Essa obseruatio é feita a partir da visão - oculis (Sêneca, Nat. Quaest., Praef) - obseruatis ac notatis signis (Cíc., Div., 1, 18). A leitura dos sinais não é fortuita, casual, aleatória - fors casus est. (Isid. Diff. app. 248) - mas baseada na razão (ratio) (Cíc., Diu., 1, 41,; Sêneca, Nat. Quaest., 2,32$)^{9}$ enquanto capacidade exlusiva do homem de pensar e ordenar logicamente os acontecimentos:

per (rationem) consequentia (homo) cernit, causas rerum videt, earumque progressus et quasi antecessiones non ignorat, similitudines comparat rebusque praesentibus adiungit atque annectit futuras [Cíc. 1 off. 4, 11-12].

A observação sistemática da natureza e da sua correspondência com os fenômenos sociais seria, em certas passagens de Cícero, tão previsível que o autor latino chega a prescindir dos deuses como emissários dos sinais, reservando-se toda a leitura à esfera da natureza:

quae (scientia diuinandi) potest esse etiam sine motu atque impulsu deorum [Cíc., Diu. 1, 49].

Em alguns casos, a leitura pode reverter da esfera natural para a própria humanidade, estabelecendo-se uma relação entre o presente e o futuro no interior das relações humanas, como deixa claro Petrônio:

Uides me: nec auguria noui nec mathematiconum caelum curare soleo; ex uultibus tamen hominum mores colligo, et cum spatiantem uidi, quid cogites scio. $[126,3]^{10}$. Veja, não conheço os augúrios nem costumo observar o céu como os astrólogos; contudo, percebo o jeito dos homens pelos seus rostos e, quando vejo alguém caminhando, descubro o que tenciona fazer.

Um conceito fundamental por detrás da racionalidade da leitura da natureza é o do destino inexorável (fatum), estabelecedor de constâncias e, por definição, oposto ao acaso. Se tudo ocorre por uma lógica humanamente compreensivel e ocorre invariavelmente, então a leitura racional é a única, fatal:

Quicquid fit, alicuius rei futurae signum est; fortuita et sine ratione uaga diuinationem non recipiunt. Cuius rei ordo est, etiam praedictio est [Sêneca, $N Q, 2,32$ ].

Tudo o que existe é presságio do que será. Os fatos casuais que escapam ao cálculo e às regras não admitem adivinhação. Se há uma ordenação nos eventos, então a predição é possivel. 
O fatum implica uma inexorabilidade advinda da sucessão natural — non id quod superstitiose sed id quod physice dicitur (Cíc., Diu., 1, 55) - de acontecimentos:

Nihil est futurum, cuius non causas id ipsum efficientes natura contineat. [Cíc., Diu., 1, 55].

Nada ocorrerá que não tenha em si mesmo, por natureza, suas causas determinadas.

A essa concepção racional da adivinhação opunha-se a predição por possessão concitatione quadam animi aut soluto liberoque motu futura praesentiunt (Cíc., Diu., 1, 18) — na qual o contato imediato com o futuro não se baseava numa leitura ou interpretação racional, mas num dom profético sobrenatural - furentis animi uaticinatio (Petrônio, 118, 6) - não compreensível pelo raciocínio humano ${ }^{11}$. Essa possessão podia dar-se tanto em estado de vigília - uaticinatio (Cíc., Diu., 2, 48; e Petrônio, 118, 6) acompanhada de um descontrole fisico por parte do possuído - soluto liberoque motu (Cíc., Diu., 1, 18); per furorem (Cíc., Diu., II, 55) - como em repouso - in quiete (Cíc., Diu., 2, 55) - por meio de sonhos - somniandi diuinatio (Cíc., Diu., 2, 48) ${ }^{12}$.

A ausência de explicação racional remete não tanto à esfera da crebilidade religio$\mathrm{sa}^{13}$, que pode revestir-se da certeza proveniente da própria fé - religiosae orationis sub testibus fides (Petrônio, 118, 6) -, quanto ao campo da superstição (superstitio) derivada da ignorância das causas - ignorantia causarum [...] operum causas nulla ratione uidere possunt, ea fieri diuino numine tuentur (Lucrécio, NR, 6, 49). $\mathrm{O}$ insucesso das predições ${ }^{14}$, tanto racionais quanto por possessão, induzia à descrença na adivinhação, atribuindo-se seus erros não a uma incapacidade temporária de homologação de fenômenos observáveis - portanto, a erros de leitura:

Signa ostendunt a dis rerum futurarum. Si qui errauerunt, non deorum natura, sed hominum coniectura peccouit. [Cíc., De Nat. Deorum, 2, 4].

Os deuses mostram o futuro por sinais. Se se engana ao interpretá-los, a culpa não é dos deuses, mas são os homens que não souberam compreender.

- mas a uma discordância derivada da própria observação dessa não correspondência: omnes opertis oculis bona sua computant (Petrônio 44, 170).

Mesmo quando uma predição revela-se justa, quem pode afirmar que não se deve ao acaso - casu (Cíc., Diu., 2, 24)? Os arúspices riem-se uns dos outros (Cíc., Diu., 2, 24), preocupam-se em enganar (Cíc., Diu., 2, 48), portanto deve-se extirpar toda superstição (Cíc., Diu., 2, 72), já que pelo esquecimento das antigas regularidades constatadas (Cíc., Diu., 1, 18), pelo pouco caso da nobreza, sobrou apenas um simulacro formal das práticas divinatórias:

Negligentia nobilitatis, augurii disciplina omissa, ueritas auspicorum spreta est, species tantum retenta. [Cíc., Diu., 1, 22]. 
Mas pela negligência da nobreza perdeu-se a disciplina augural, a verdade dos auspícios é desprezada, apenas se mantém a aparência ${ }^{15}$.

\section{A evidência das camadas populares}

I saw a woman sit alone.

Charada popular anglo-saxônica ${ }^{16}$.

A tradição textual refere-se a um espectro de atitudes para com a adivinhação e reflete, na diversidade de opiniões retratadas, a convivência, contraditória e conflitan$\mathrm{te}^{17}$, de diferentes pontos de vista, tais como observados por autores das elites romanas. A maneira como as camadas populares ${ }^{18}$ encaravam a adivinhação, por sua parte, devia - variar igualmente bastante, embora não possuamos evidências numerosas, e nem os estudos sobre a cultura popular antiga estejam desenvolvidos ${ }^{19}$. As inscrições parietais, em especial provenientes de Pompéia, atestam que a adivinhação encontrava-se radicada nas preocupações populares. Talvez o exemplo mais claro, a esse respeito, seja a seguinte charada popular, encontrada na Via di Nola em Pompéia (CIL 4, 1595):

Serpentis lusus si qui sibi forte notauit

Da serpente as charadas se alguém para si por acaso notou

Sepumius iuuenis quos facit ingenio

Sepúmio o jovem as quais faz com imaginação

Spectator scaenae siue es studiosus equorum

O espectador da cena ou és torcedor dos cavalos

Sic habeas lances semper ubique pares

Então tenhas pratos sempre em toda parte iguais

Interpretação:

Se alguém por ventura notar estes jogos da serpente,

Que o jovem Sepúmio faz com engenho, então reflita:

Se és freqüentador do teatro ou das corridas de cavalo,

Então tenhas consigo sempre, em toda parte, equilibrados os pratos da balança.

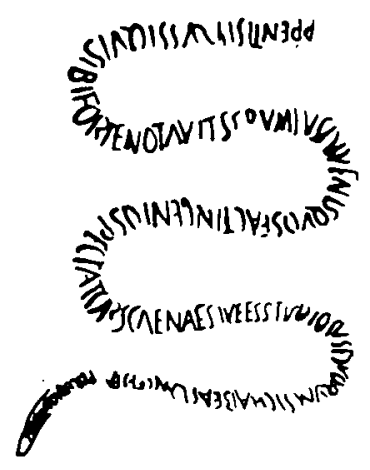


O autor propõe, a um só tempo, uma charada (lusus) e a apresenta como uma piada (lusus), advertindo, desde o início, o leitor para o caráter zombeteiro do seu poema. Logo no primeiro verso, de forma metalingüística, refere-se à forma inusual, imitando uma serpente, com a qual compôs seus versos ("se alguém notou"). A alusão à serpente não se restringue à forma do poema, mas refere-se ao próprio enigma ${ }^{20}$. De fato, a associação de serpente às charadas encontrava-se arraigada na mente popular, tendo em vista que, na mitologia greco-latina, Apolo, ainda adolescente, matara a serpente Píton (=advinho) que perseguia sua mãe Latona e que, esfolada, sua pele servira para cobrir a trípode sobre a qual se sentava a Pitonisa de Delfos para proferir seus oráculos. Assim, no próprio templo de Apolo em Delfos, encontrava-se uma serpente de bronze de três cabeças. A associação da serpente com a advinhação de enigmas encontrava-se tão difundida no primeiro século d.C. que o autor dos Atos dos Apóstolos (XVI, 16), escrevendo talvez pouco após a destruição de Pompéia (provavelmente a partir de 100 d.C.), utilizou-se da expressão pneuma Pythona ( literalmente, espírito da serpente Píton) para referir-se, como em geral se traduz no Novo Testamento, ao espírito da adivinhação. De qualquer forma, a "charada da serpente" lembraria ao pompeiano, de imediato, que se tratava de um jogo de adivinhação.

A presença do autor no segundo verso vem acompanhada do epiteto "o jovem", que justifica o caráter bem-humorado da obra. Em seguida, o autor anuncia que a elaboração do poema, em termos formais - pela imitação da serpente e pelos versos contou com sua imaginação criativa (ingenium). Na verdade, sob este termo encontrase a própria definição da sua obra poética como uma construção humana, algo elaborado racional e esteticamente. De fato, ingenium define aquilo que é próprio do genius (talento, índole) enquanto atributo que diferencia o homem, ser pensante, dos outros animais. Algo produzido (gigno), gerado na mente humana. Esta capacidade humana explica, portanto, a elaboração do poema, enquanto expressão estética e enquanto enigma a ser decifrado pelo leitor.

O terceiro verso enuncia dois locais e duas situações sociais a serem postos em questão: o teatro e as corridas de cavalos. Estabelece-se, então, uma assimetria entre a passividade do espectador do teatro e a atividade do torcedor (studiosus) das corridas de cavalos. Embora ambos assistam a espetáculos públicos, o autor opõe a observação (spectatio) do palco (scaena) no teatro à excitação, desejo e torcida pela vitória deste ou daquele. No primeiro caso, portanto, trata-se de observar o desenrolar da peça de teatro, cujo desfecho não é conhecido de antemão. No segundo, mais que observar o desenrolar da corrida, a torcida (studium) por um dos cavalos em disputa constitui a essência da participação. Estas duas situações sociais diversas justificam a utilização, pelo autor, do plural "charadas" (lusus), pois, efetivamente, as duas atividades põem questões e exigem respostas diversas.

No quarto verso, o enunciado único das duas charadas apresenta-se sob o manto diáfano da metáfora: "tenhas sempre, em toda parte, os dois pratos iguais". Lanx designa prato de balança e, portanto, dois pratos iguais significam, necessariamente, os 
dois pratos da balança equilibrados. Mas, por que os pratos equilibrados se referem ao teatro e aos cavalos? Antes de mais nada, deve-se lembrar que o verbo ter (habere) significa, também, considerar, estimar, avaliar. Neste caso, referindo-se às peças teatrais, a frase significa que se deve preparar para qualquer desfecho, não necessariamente o mais esperado ou provável. O predomínio, no teatro pompeiano dos últimos tempos, de representações realistas, grandiloqüentes e que, bem ao gosto popular, fugiram dos padrões eruditos clássicos explica o papel do elemento emocionante e inesperado no desenrolar da peça. As repetições das obras clássicas eram preteridas em favor das "histórias de aventura". O culto aos clássicos não encontrava consenso nem mesmo entre o público erudito. Tácito, no seu De Oratoribus, retrata bem a disputa entre os antiquisantes e os inovadores, aceitando estes as novas correntes artísticas, atacadas por aqueles. $\mathrm{O}$ próprio Cícero, segundo o relato de Tácito (De or., 22, 1), travara a mesma batalha com os seus contemporâneos, pois eles admiravam os antigos enquanto ele preferia a eloqüência da sua própria época. De toda forma, ainda que houvesse críticas, por parte de setores da erudição, ao inesperado no teatro de fins do primeiro século d.C., a alusão de Sepúmio, em seu poema, apenas pode referir-se à necessidade, por parte do espectador, de contar com desfechos inusuais. Trata-se, portanto, da aguda percepção, por parte do autor, de uma característica essencial da sua época: o gosto pelo novo, a ojeriza da repetição inócua dos modelos clássicos.

Por outro lado, a referência às corridas de cavalos deve ser entendida no contexto da paixão popular por esse esporte. No entanto, à diferença do teatro, o público organiza-se, aqui, em torcidas, esperando por um resultado favorável ao seu cavalo. Novamente, os pratos da balança referem-se ao acaso, à Fortuna em cujas mãos se encontra o resultado inesperado. Neste momento, ao final do poema e quando a solução se apresenta clara, o inesperado, resposta da charada, impulsiona o leitor ao primeiro verso e à própria forma do grafite, à serpente oracular, pois apenas a adivinhação pode, de antemão, decidir-se por um dos pratos da balança.

\section{Conclusão}

A adivinhação, enquanto conjunto multifacetado de práticas sociais, não se apresentava univocamente para os romanos como uma função social mas, pelo contrário, como desencadeador de contradições e conflitos (Giddens, 1979, p. 131) tanto no nível das ideologias dominantes como das subalternas. A tensão dialética entre o inexorável e metódo (fatum) e o casual e aleatório (fors), raiz última das contradições das práticas divinatórias e suas racionalizações, permearia todo o pensamento romano até o advento de um outro tipo de ordenação da relação entre presente e futuro a partir do quarto século d.C.: non est augurium in Iacob, nec diuinatio in Israel (Num. 23, 23). 


\section{Notas}

1- São atestadas 9 diuinationes: furoris (Cíc., Diu., 1, 4); augurum (Cíc., Diu., 2, 74); auium (Cíc. Diu., 2, 77); somniorum (Aug. Ciu. 8, 16, p. 345D); futurorum (Plínio, N.H., 37, 155); stoicorum (Cíc. Diu., 2, 21); animae (Tert., Anim., 24); haruspicum et uatum (Aug. Ciu., 8, 16, p. 345D).

2-Por último veja-se Tupet, 1984; e Scheid, 1985.

3- Veja-se frase de Dumézil (1974) citada no texto; cf. Tupet, 1984, p. 235: "toute la société était obsédée par des croyances aux puissances occultes". Assim, Denise Grodzynsky (1974, p. 267), baseando-se em Cramer (1954), tendia a absolutizar os motivos políticos da repressão à adivinhação, desconsiderando passagens bem conhecidas de Tito Lívio $(4,30 ; 25,1)$, Catão (5, 4) e Columela $(11,1,22)$ que demonstram uma preocupação de não perturbar a pax deorum. Cf. Le Glay, 1972, p. 540.

4- A disputa entre patrícios e plebeus quanto aos cargos ligados à adivinhação é freqüentemente citada na tradição textual: crearent consules ex plebe, transferrent auspicia, quo nefas esset (Liv. 7, 6, 10); penes patricios auspicia esse [...] patricios solos [...] habere auspicium domi militiaeque; plebes ad id maxime indignatione exarsit, quod auspicari tamquam in uisi diis immortalibus negaretur posse (Liv. 4, 6, 3).

5- quod de caelo auspicari ius neminist praeter magistratum. Varro frag. apud Non., p. 92, 6.

6- Para Tupet (1984, p. 206) superstitiones temporis illius (sc. primum saeculum post Christum), quibus non solum uolgus erat imbultum, sed etiam ciues nobiles atque eruditi. No entanto, a documentação disponível permite entrever nos dois segmentos sociais citados pela autora urna atitude bastante diversa da superstição generalizada. Para um exemplo de uma posição das classes populares, veja-se Petrônio 44, 17-18 e, para uma posição enudita, Sêneca, Nat. quaest., 2, 32.

7- Por exemplo, CIL 4, 1595.

8- O exemplo mais claro da ambigüidade para com os procedimentos divinatórios encontra-se, sem dúvida, em Cícero. Compare-se, por exemplo, duas frases antagônicas: quis uero non uidet, in optima quaque re publica plurimum auspicia et reliqua diuinandi genera ualuisse? Quis rex unquam fuit, quis populus, qui non uteretur praedictione diuina? (Cíc., Diu., 1, 43). e at omnes reges, populi nationes utuntur auspiciis. Quasi uero quidquam sit tam ualde quam nihil sapere uulgare, aut quasi tibi in iudicando placeat multitudo? (Cíc., Diu., 2, 39). Cf. Petrônio, 118, 6.

9- Cf. Petrônio 112, 8.

10- Cf. Cíc., Diu., 2, 45: quis enim uidet et formas et mores et plerosque status ac motus effingere a parentibus liberos.

11- Carent autem arte (Cíc., Diu., 1, 18).

12- Cf. Suetônio, Vita Neronis, 46.

13- Cf. Günther Schmidt, 1985, p. 17: alle Mythologie beherrsche die Natur nur in der Einbildung.

14- Cíc., Diu., 2, 39: Non necesse est fateri, partim horum errore susceptum esse, partim superstitione, multa falendo?; e 2, 24: quid ego haruspicum responsa commemorem (possum equidem innumerabilia), quae aut nullos habuerint exitus aut contrarios?

15- A distinção entre augurium e auspicium apresenta-se clara em Sérvio (ad Aen., 1, 398): augurium et petitur et certis a uibus ostenditur, auspicium qualibet aui demonstratur et non petitur: quod ipsum tamen species augurii est. Sobre o suposto declínio do augúrio em fins da república e no início do principado, comparem-se as opiniões divergentes de Scheid (1985, p. 46) e 
Dumézil (1974, p. 598). As evidências epigráficas parecem favorecer a posição de Scheid: veja em particular CIL 6, 36.841; e Tácito, Ann., 12, 23.

16- Resposta da charada: $a$ hen.

17- Veja a respeito Hofstadter, 1968, p. 458; e Brock, 1978, p. 20.

18- As camadas populares são consideradas aqui, seguindo E. P. Thompson (1968, p. 939), not as a thing, it is a happening.

19- Sobre a cultura popular, com bibliografia, veja Funari, 1989. Sobre a history from below, veja, por último, Hill, 1989, p. 12; Giddens, 1987, p. 217; Rustin, 1989, p. 68; e Wood, 1989, p. 4.

20- Cf. Ignatius, Ep. 2: "em todas as circunstâncias, seja sábio como a serpente, ainda que sempre inofensivo como uma pomba" (grifo nosso).

\section{Referências Bibliográficas}

BROCK, W. R. Conflict and Transformation. London: Penguin, 1978.

DUMÉZIL, G. La Religion Romaine Archaique. Paris: Payot, 1974.

FUNARI, P. P. A. Cultura popular na Antiguidade clássica. São Paulo: Contexto, 1989.

GIDDENS, A. Central Problems in Social Theory. London: MacMillan, 1979.

GIDDENS, A. Social Theory and Modern Sociology. Cambridge: Polity, 1987.

GRANT, M. Cities of Vesuvius. London: Penguin, 1979.

GRODZYNSKY, D. Par la bouche de l' Empereur. In: AA.VV. Divination et Rationalité. Paris:

Du Seuil, 1974, p. 267-94.

GÜNTHER SCHMIDT, E. Ökonomie, Kunst und Altertum bei Marx. Eirene, Praga, v. 22, p. $5-20,1985$.

HILL, C. History and the Present. London: South Palace Ethical Society, 1989.

HOFSTADTER, R. The Progressive Historians. New York: Vintage, 1968.

LE GLAY, M. Magie et sorcellerie à Rome au dernier siècle de la république. Mélanges Jacques Heurgon, Paris: De Boccard, 1972, p. 525-50.

RUSTIN, M. The politics of Post-Fordism: or the trouble with "New Times". New Left Review, Londres, v. 175, p. 54-77, 1989.

SCHEID, J. Religion et pitié à Rome. Paris: Découverte, 1985.

THOMPSON, E. P. The making of the English Working Class. London: Penguin, 1968.

TUPET, A.-M. La mentalité superstitieuse à l'époque des Julio-Claudiens. Révue des Études Latines, Paris, v. 62, p. 206-35, 1984.

WOOD, E. M. Peasant-citizen and slave. London: Verso, 1989. 

das práticas divinatórias entre os romanos

FUNARI, P. P. A. Reason, possession, derison: three expression of the divinatory practices among the Romans. Clássica, São Paulo, 4: 135-144, 1991.

ABSTRACT: The Roman divination practices have often been considered as a unitary praxis including ideological representation and ritual practising. This paper aims at discussing some aspects of the divination as it was viewed by the Roman of the late Republican and early Principate times having in mind the inner contradictions within the Roman thought on prediction practices. The author studies the main standpoints relating to divinatory activities. The articulation of the different interpretations enables us to understand better the tensions and contradictions that the divinatory practices and conceptions embodied in the Roman society.

UNITERMS: Divination, rituals, roman religion, roman society. 